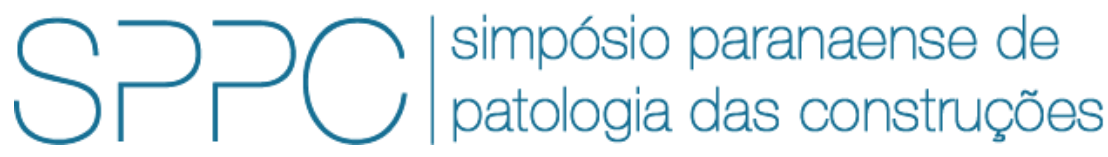

ISSN 2526-7248 artigo 2SPPC1004, pp. 34-47, 2017

\title{
Análise de um edifício em concreto armado com problemas de corrosão de armaduras
}

\author{
Marcus Vinícius Fernandes Grossi ${ }^{1}$ \\ ${ }^{1}$ Engenheiro Civil - Especialista em Excelência Construtiva e Anomalias, Fernandes \& Grossi \\ Engenheiros Associados Ltda., marcus@fernandesgrossi.com.br
}

\begin{abstract}
Resumo: A análise de corrosão em estruturas de concreto armado é um tema que vem sendo estudado há bastante tempo, seus métodos de inspeção e diagnóstico, discutidos e aplicados por diversos profissionais. Porém, seus estudos acadêmicos e teóricos muitas vezes não chegam de maneira prática e objetiva aos profissionais (engenheiros, peritos, inspetores, auditores, projetistas, etc.) que atuam e vivenciam diretamente com esse tema em seu dia-a-dia. Este trabalho tem como objetivo exemplificar um método prático de inspeção de estruturas de concreto armado sujeitas a corrosão de armaduras, a partir da análise do desempenho estrutural de uma edificação habitacional de aproximadamente 28 anos por meio de análise documental, inspeção visual e ensaios expeditos, a fim de realizar o diagnóstico das principais causas da corrosão de armaduras. Este estudo foi feito através de pesquisa bibliográfica, ensaios expeditos e inspeção em campo. A partir dos resultados, foi possível concluir que as principais causas de corrosão são: (a) o baixo cobrimento das armaduras; (b) a carbonatação do concreto; (c) a baixa resistência do concreto; (d) os ninhos de concretagem; (e) a lixiviação do concreto e (f) falta de repintura (manutenção preventiva). As ações de recuperação necessárias consistem em reparo de todos os pontos de corrosão, realizando a limpeza das armaduras, acréscimo de seção de aço onde necessário e recomposição do concreto. Após isso, será necessário o tratamento das causas que geram a corrosão.
\end{abstract}

Palavras-chave: Corrosão. Patologia. Inspeção. Estruturas. Diagnóstico.

Abstract: The analysis of corrosion in reinforced concrete structures that has been studied for a long time and its methods of inspection and diagnosis are discussed and applied by several professionals. However, the academic studies on the subject often do not reach in a practical and objective way to professionals (engineers, experts, inspectors, auditors, designers, etc.) who work directly with this theme in their daily lives. This work aims to exemplify a practical method of inspection of reinforced concrete structures subject to reinforcement corrosion, analysing the structural performance of a 28years-old building, through documentary analysis, visual inspection and expedited tests, to perform the diagnosis of the main causes of corrosion of reinforcements. This study was done through bibliographic research, expedited trials and field inspection. From the obtained results, it was possible to conclude that the main causes of corrosion are: (a) the low cover of the reinforcement; (b) the carbonation of the concrete; (c) low resistance of concrete; (d) to concrete nesting; (e) concrete leaching and (f) lack of repainting (preventive maintenance). The necessary recovery actions consist on the repair of all corrosion points, cleaning the reinforcements, addition of steel section where necessary, and recomposing the concrete. After those procedures, it is necessary to treat the causes that generate the corrosion.

Keywords: Corrosion. Pathology. Inspection. Structures. Diagnosis. 


\section{Introdução}

Neste trabalho é apresentado os resultados da avaliação da inspeção da estrutura de concreto armado de uma edificação residencial de aproximadamente 28 anos na zona sul da cidade de São Paulo, com foco nas anomalias decorrentes de corrosão da armadura, a fim de elaborar um diagnóstico, um prognóstico para servir de subsídio às recomendações de recuperação e reparo para preservação de sua integridade e aumento de sua vida útil.

\section{Histórico e características da edificação}

Através de entrevista com a síndica e o zelador foram levantadas informações sobre o histórico de uso, conservação, manutenção e modificações, assim como das eventuais anomalias observadas por eles ou pelos demais moradores.

Foi feita análise documental e de alguns projetos que contribuíram para identificação dos elementos estruturais, mas não forneceram detalhamento de armadura, memória de cálculo e outras considerações. As características estruturais colhidas nos projetos de estrutura são $f_{c k}=18 \mathrm{MPa}$ e cobrimento de armadura de $1,5 \mathrm{~cm}$ geral para todos os elementos estruturais.

O edifício foi projetado e comercializado para finalidade de uso residencial multifamiliar, o que não houve alteração.

Existe manual de uso, operação e manutenção, porém não contém informações sobre o sistema estrutural da edificação. A estrutura da edificação não possui plano e registros de manutenções preventivas e corretivas, mas segundo relatos foram feitos reparos no sistema de impermeabilização do piso do pavimento térreo que possibilitava a infiltração de água para o $1^{\circ}$ SS pela junta de movimentação. Ocorreram outros pontos de infiltração nas paredes dos subsolos que segundo relatos foram sanados.

Erroneamente os responsáveis pela manutenção, lavam com água corrente as lajes dos subsolos, que não são impermeabilizadas, fazendo com que a água percole por frestas, trincas e poros do concreto, lixiviando esses elementos, diminuindo a alcalinidade do concreto e consequentemente diminuindo sua vida útil [1].

Existem pontos de reparo da laje dos subsolos que provavelmente são reparos de armadura exposta corroída, porém não há registros ou ciência dos envolvidos de quando e como foram feitos. 


\section{Método de inspeção}

O método de inspeção adotado no presente trabalho fundamenta-se no "Procedimento Recomendado Orientativo para Inspeção de Estruturas de Concreto da ABECE" [2], através de anamese, inspeção visual e ensaios expeditos, conforme a figura 1, que apresenta a sequência realizada para análise de um "problema patológico" em edificações, com intuito de analisar as suas causas, para que seja proposta uma solução de tratamento em sua origem.

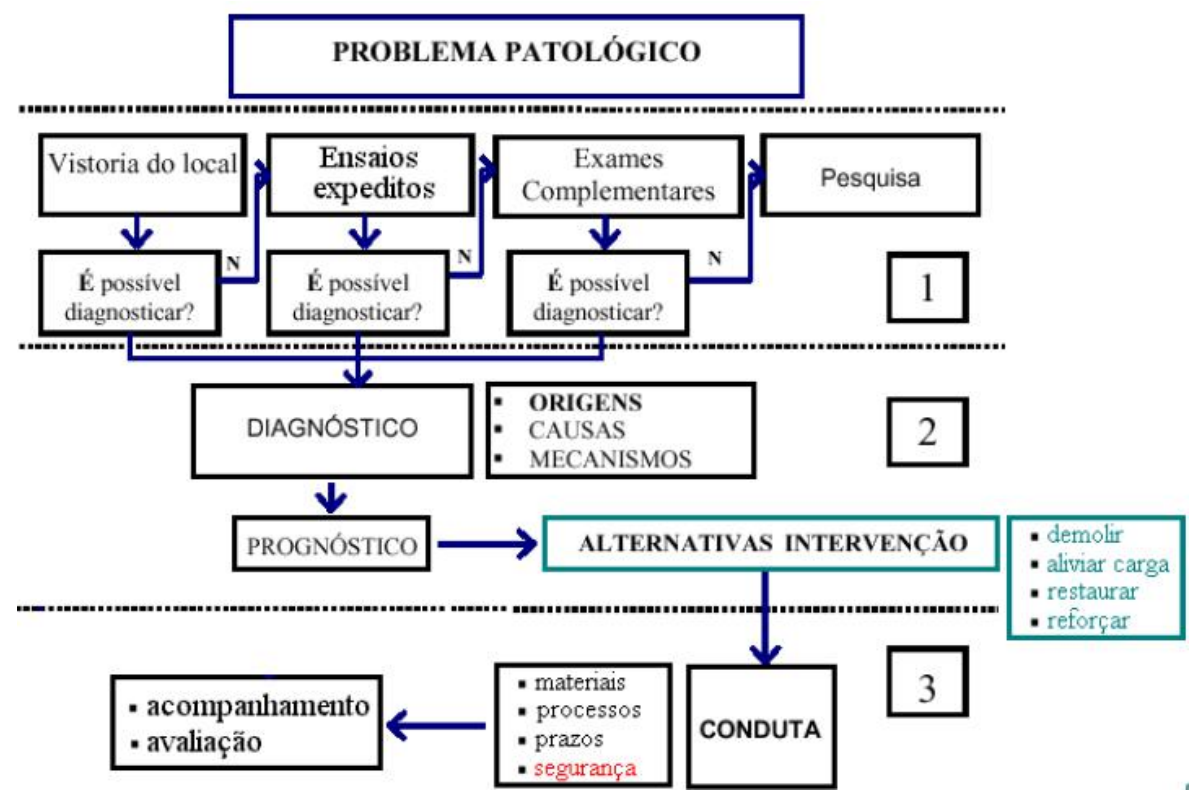

Figura 1: Análise de Problema Patológico [3]

\subsection{Inspeção visual}

A inseção visual foi realizada a olho nú em $100 \%$ da área dos dois subsolos, conforme croquis representados pela Figura 2 e Figura3.

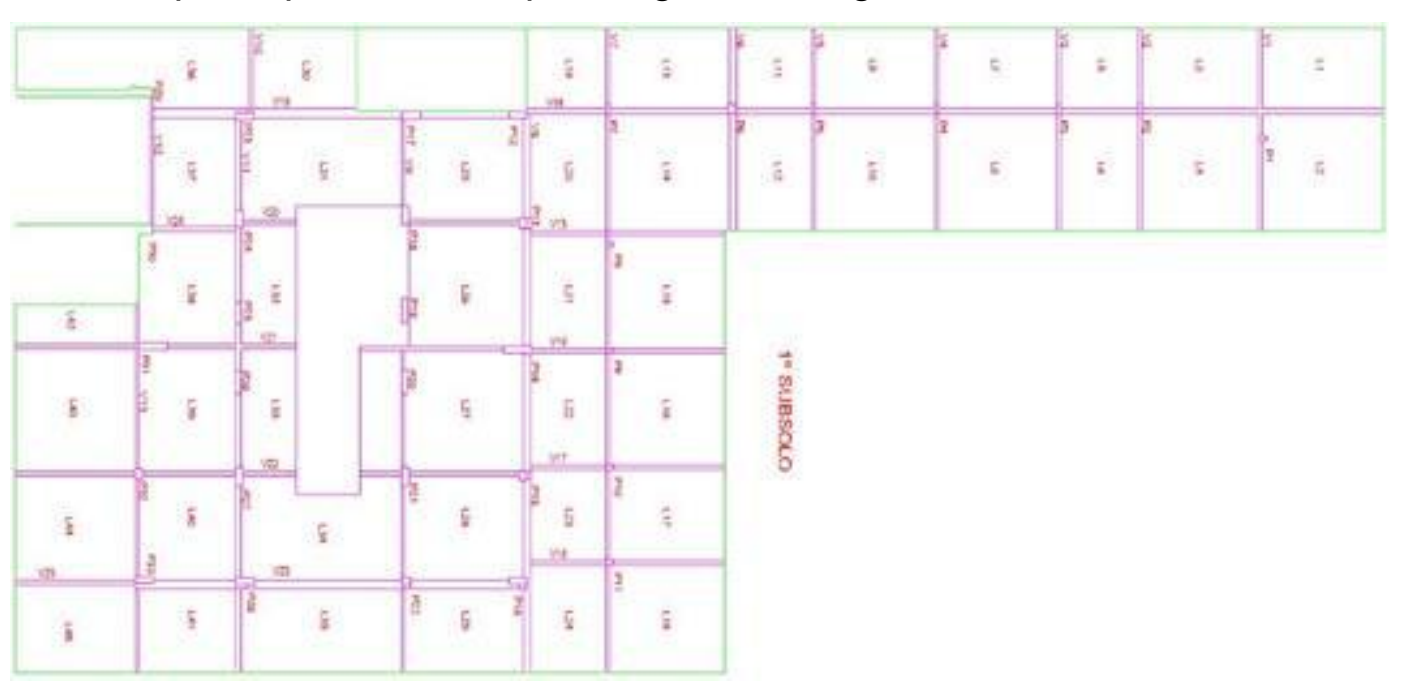

Figura 2: Croqui da área inspecionada no $1^{\circ}$ subsolo 


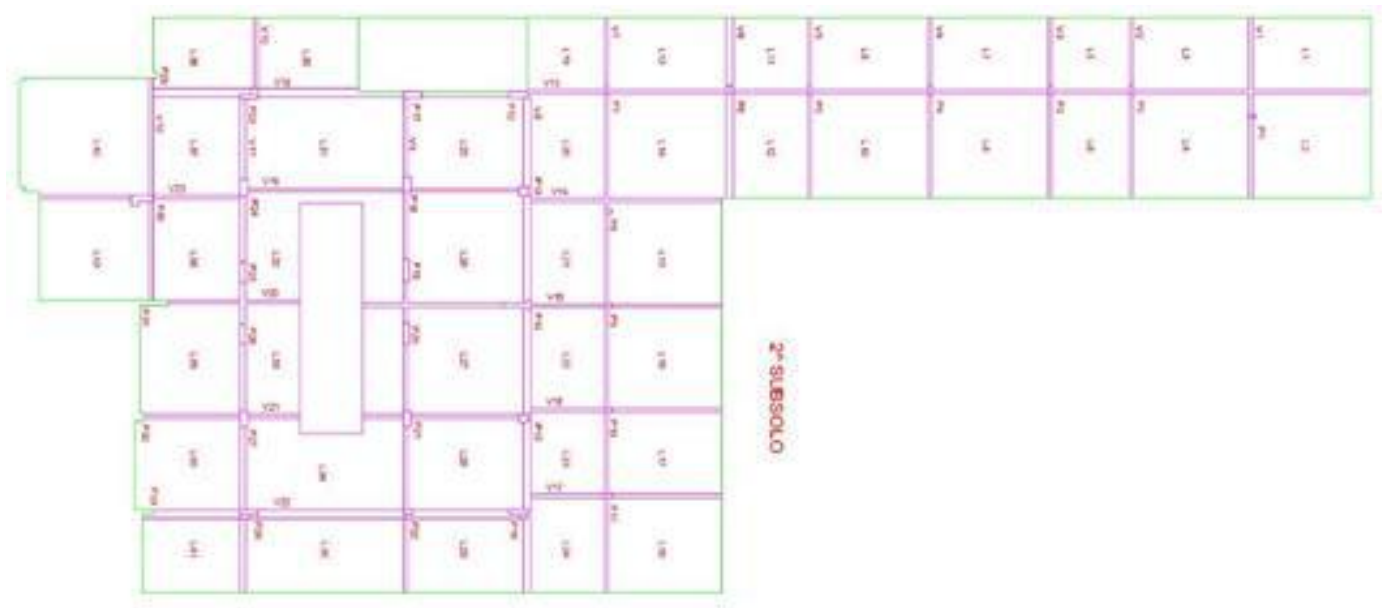

Figura 3: Croqui da área inspecionada no $2^{\circ}$ subsolo

Todas as anomalias identificadas foram quantificadas, registradas fotograficamente e representadas em croqui.

\subsection{Ensaios expeditos}

Apesar da inspeção visual ser rápida e eficaz para avaliação do estado de conservação ele é limitado à análise superficial. Por isso foram realizados alguns ensaios expeditos, sendo eles:

- profundidade de carbonatação;

- medição do cobrimento de concreto;

- análise dimensional de seção de armaduras.

\subsubsection{Profundidade de carbonatação}

A profundidade de carbonatação foi realizada, conforme método descrito na BS EN 14630 [4], através de fratura do concreto são e aplicação de solução de fenolftaleína diluída $1 \%$, que reage com o concreto deixando a região carbonatada $(\mathrm{pH} \leq 9)$ incolor e a região ainda alcalina na cor rosa/magenta (Figura ).
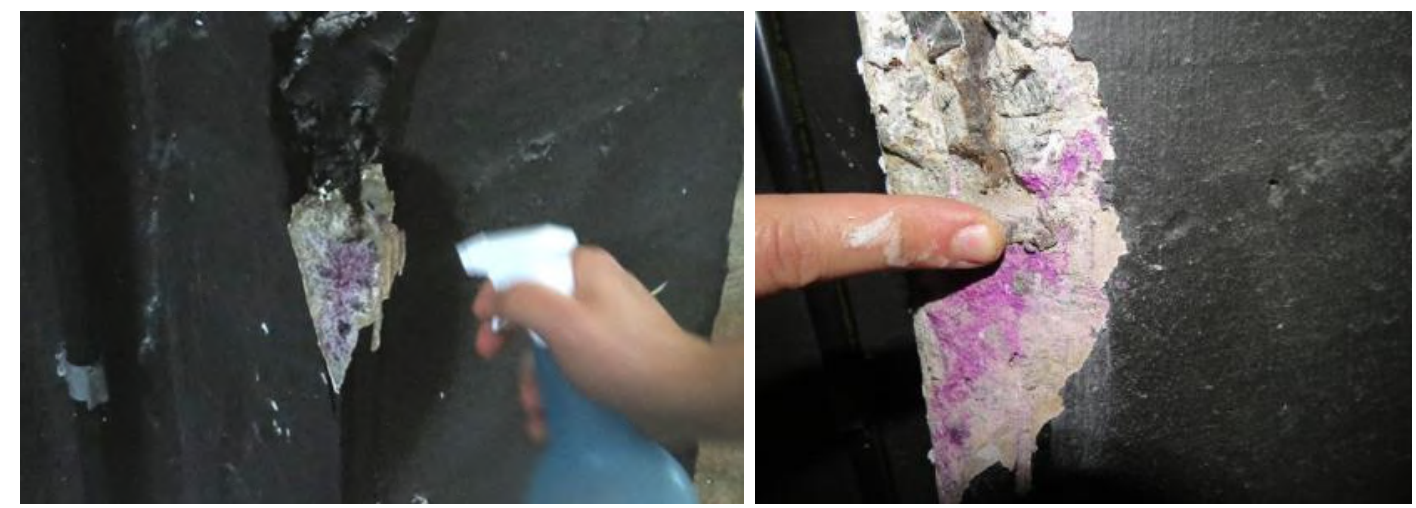

Figura 4: Ensaio de medição de profundidade de carbonatação 
Por ser um ensaio parcialmente destrutivo só foi permitido a realização de 4 amostras, determinadas empiricamente nos locais considerados mais representativos, sendo 2 amostras em cada pavimento, uma realizada na região frontal e outra na região dos fundos. Sempre no terço médio de pilares que não apresentavam trincas ou desplacamento na região, pois essas anomalias permitiram que a carbonatação se desse mais rápido em pontos mais profundos, distorcendo os resultados que seriam extrapolados para toda estrutura.

Em cada amostra foi realizada a medição de 10 pontos de profundidade de carbonatação para determinação da espessura média carbonatada, com base na média aritmética das medidas [4].

\subsubsection{Cobrimento de concreto}

A medição da espessura de cobrimento de concreto foi realizada em todos os pilares da área inspecionada conforme Figura 5, para verificar se estavam atendendo ao cobrimento de projeto. Com um pacômetro com capacidade de medição de até $12 \mathrm{~cm}$ de profundidades, foram medidas as armaduras principais e secundárias. Em cada pilar foram medidas duas faces, em três alturas distintas (terço superior, médio e inferior).
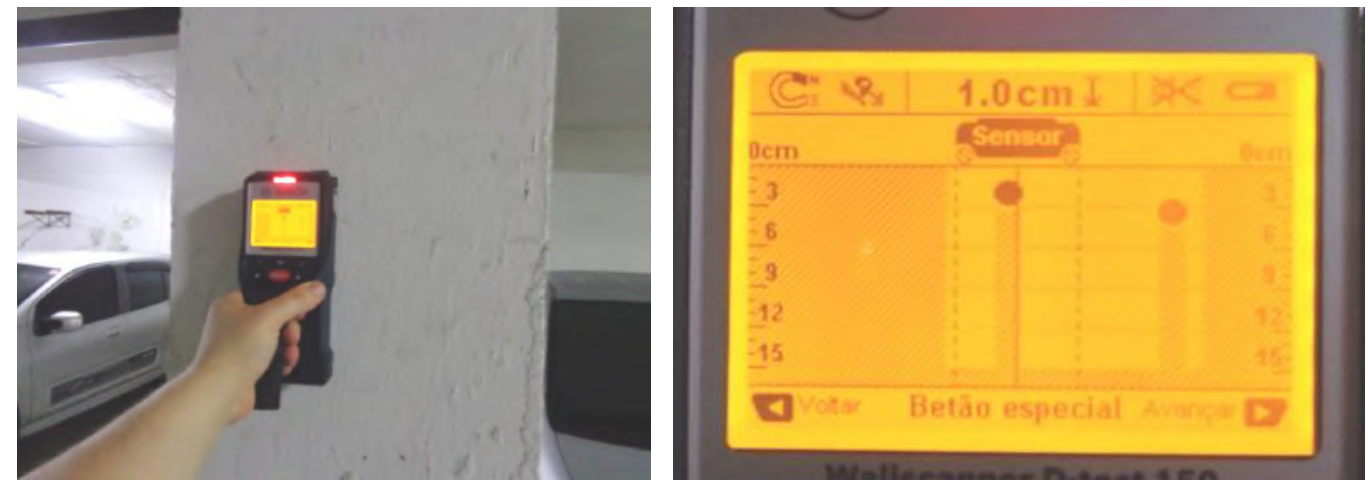

Figura 5: Medição do cobrimento de armaduras

\subsubsection{Análise dimensional da seção de armadura}

A análise dimensional da seção de armaduras foi realizada em todos os pontos com armadura exposta, apenas em locais acessíveis, sem a necessidade de fratura ou retirada de cobrimento parcialmente solto, conforme exemplo na Figura6.
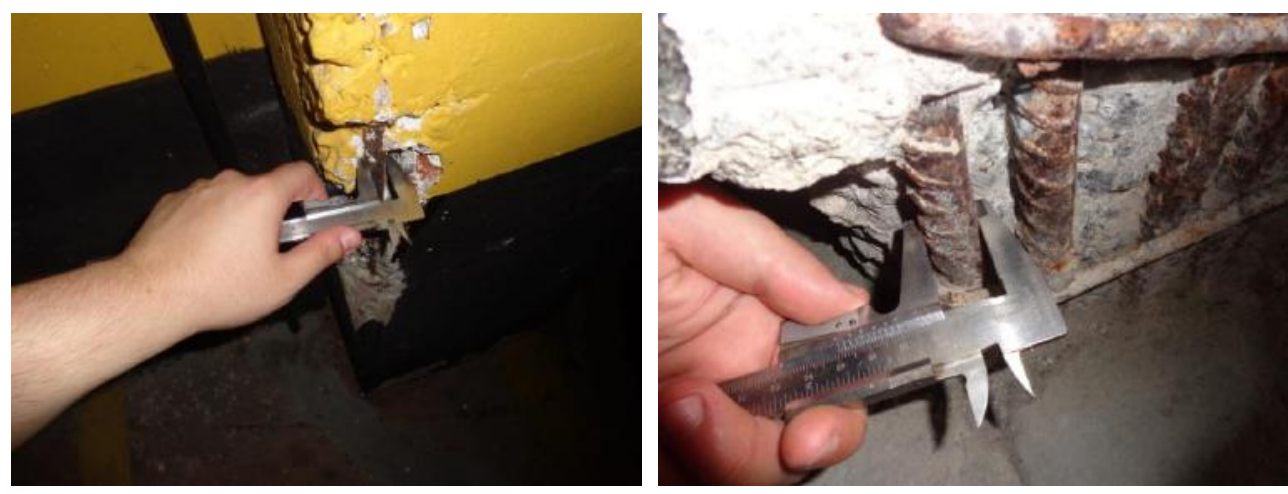

Figura 6: Medição do diâmetro da armadura principal de pilar 


\section{Resultados e discussão}

A inspeção visual apontou um estado avançado de oxidação de armadura, aparecendo de maneira generalizada nas lajes e vigas, principalmente nos locais com manchas de umidade e infiltração, em conjunto com fissuração e desplacamento do cobrimento de concreto. A Figura 7 ilustra basicamente 0 contexto geral da estrutura.
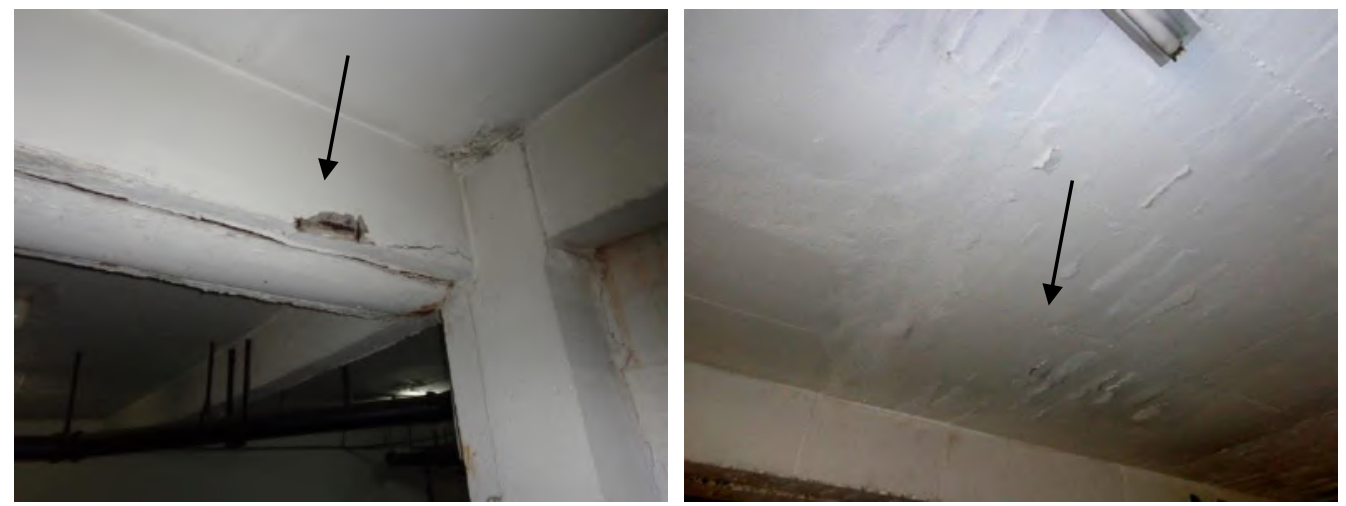

Figura 7: Armadura exposta corroída devido a infiltração e baixo cobrimento

$\mathrm{Na}$ grande maioria dos pontos com desplacamento foi possível constatar cobrimento inferior ao determinado em projeto. Tal fato não surpreende, pois na época de construção da edificação dificilmente eram utilizados espaçadores de armaduras.

Nos croquis da Figura 8 e Figura 9 estão registradas todas as anomalias constatadas.

A análise quantitativa das anomlais seguem na Tabela 1. Esse levantamento se deu apenas por analise visual das anomalias aparentes, não sendo quantificando, por exemplo, as áreas com corrosão internos, que só poderão ser identificados após escarificação dos elementos estruturais durante o processo de recuperação. Para compensar essa diferença quantitativa, foi considerado um acréscimo de área, estimando-se escarificação de $50 \mathrm{~cm}$ além dos pontos visíveis oxidados.

Tabela 1: Quantitativo das áreas degradadas

\begin{tabular}{ccc}
\hline \multirow{2}{*}{ Anomalia } & \multicolumn{2}{c}{ Local } \\
\cline { 2 - 3 } & 10 SS & 20 SS \\
\hline Armadura Exposta & $179,09 \mathrm{~m}^{2}$ & $84,08 \mathrm{~m}^{2}$ \\
\hline Ninho de Concretagem & $0,00 \mathrm{~m}^{2}$ & $44,93 \mathrm{~m}^{2}$ \\
\hline Reparo Danificado & $12,88 \mathrm{~m}^{2}$ & $20,12 \mathrm{~m}^{2}$ \\
\hline Reparo Antigo & $14,68 \mathrm{~m}^{2}$ & $45,88 \mathrm{~m}^{2}$ \\
\hline Junta de Dilatação & $49,10 \mathrm{~m}^{2}$ & $49,10 \mathrm{~m}^{2}$ \\
\hline Infiltração & $3,09 \mathrm{~m}^{2}$ & $7,02 \mathrm{~m}^{2}$ \\
\hline
\end{tabular}


GROSSI, M.V.F., ANÁLISE DE UM EDIFÍCIO EM CONCRETO ARMADO COM PROBLEMAS DE CORROSÃO DE ARMADURAS. $2^{\circ}$ Simpósio Paranaense de Patologia das Construções (20 SPPC), artigo 2SPPC1004 pp. 34-47, 2017. DOI: 10.4322/2SPPC.2017.004

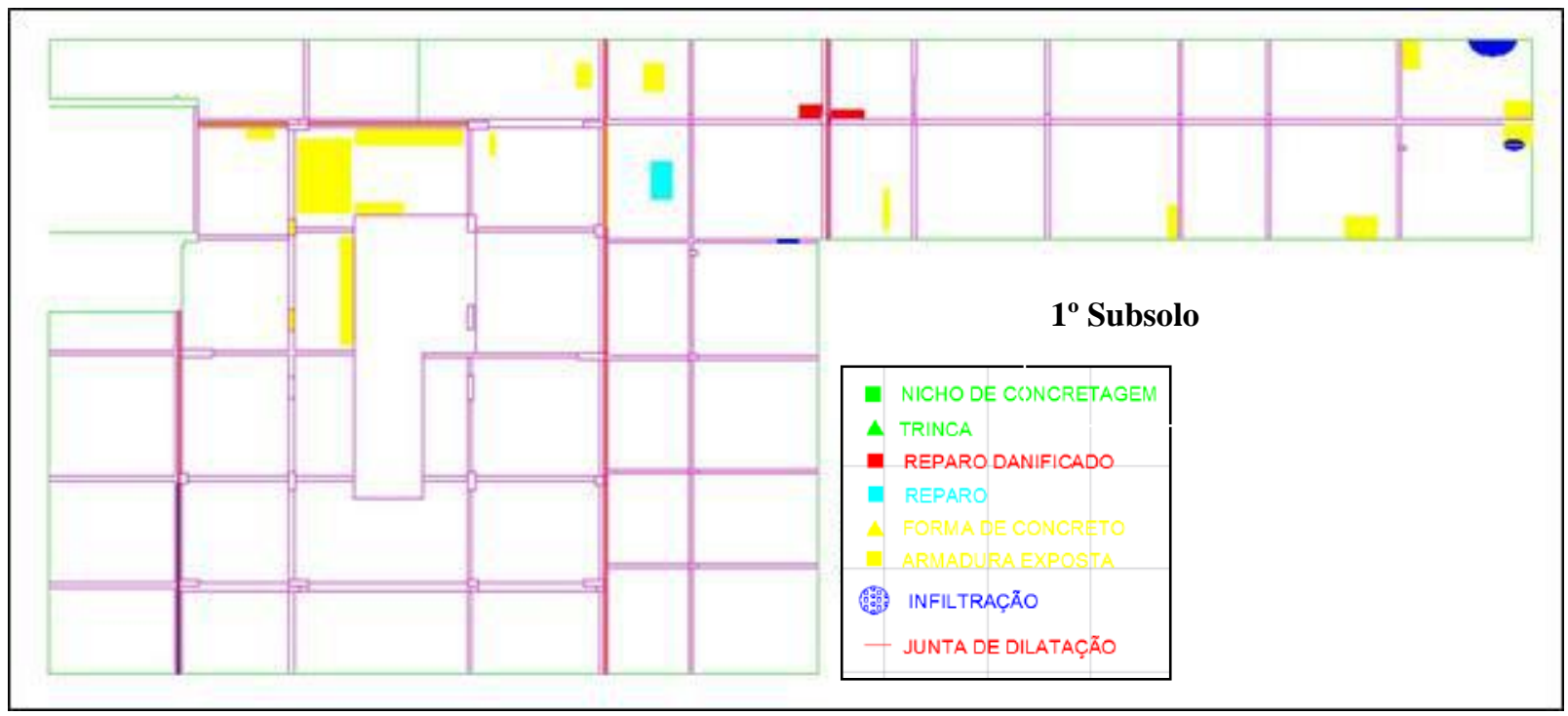

Figura 8: Croqui das anomalias do $1^{\circ}$ subsolo

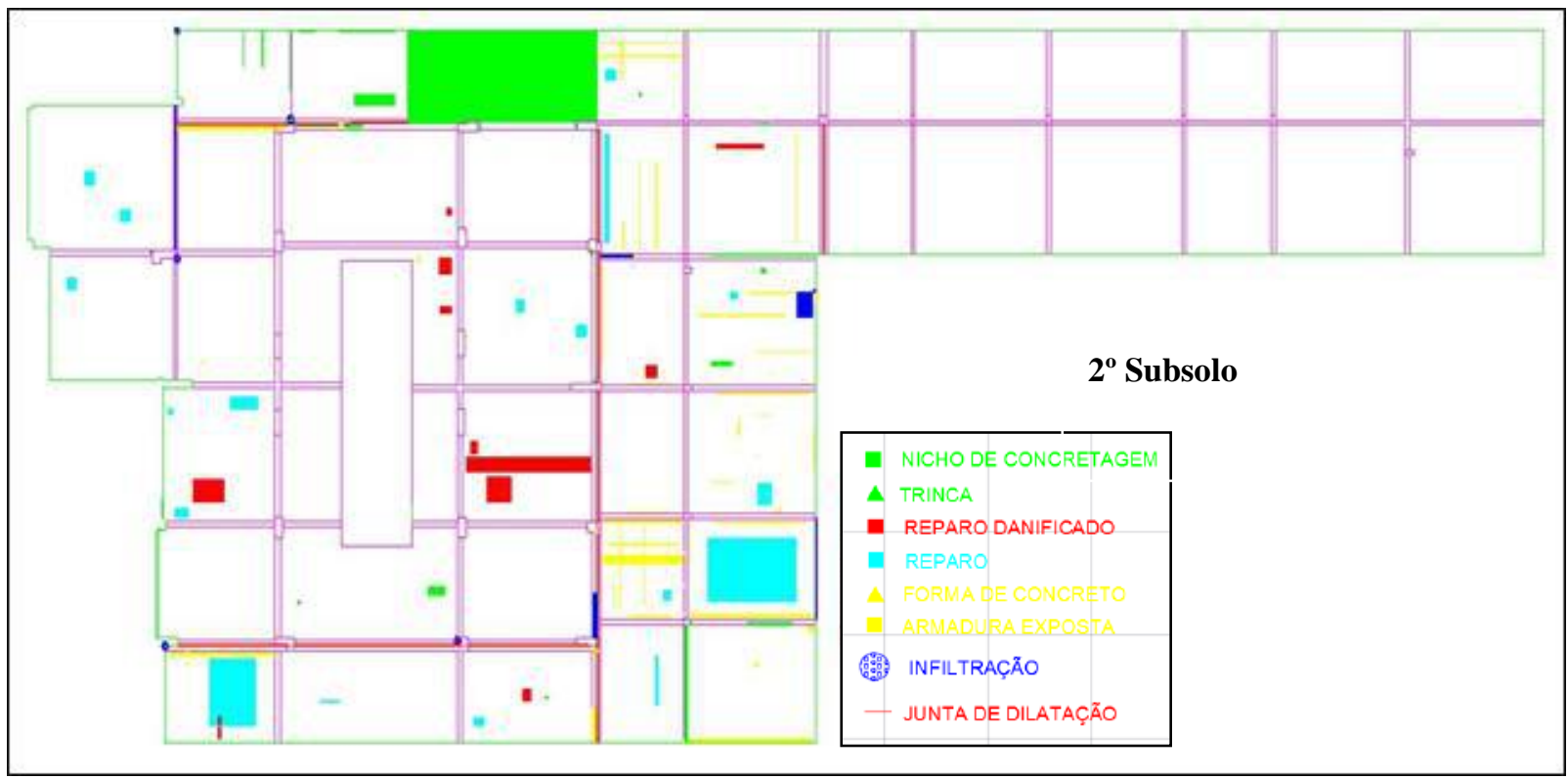

Figura 9: Croqui das anomalias do $2^{0}$ subsolo

\subsection{Carbonatação}

A Tabela 2 traz os valores médios de profundidade de carbonatação, medidos nas 4 amostras. A partir deles calculou-se a espessura média carbonatada de 10,2mm, com coeficiente de variação de $2 \%$. 
Tabela 2: Profundidade de carbonatação medida

\begin{tabular}{cc} 
Local & Espessura Carbonatada (mm) \\
\hline A1 & 10,1 \\
\hline A2 & 10,4 \\
\hline A3 & 10,0 \\
\hline A4 & 10,1 \\
\hline Média & $\mathbf{1 0 , 2}$ \\
\hline Desvio Padrão & $\mathbf{0 , 2}$ \\
\hline CV & $\mathbf{2 \%}$
\end{tabular}

Tendo-se a espessura da frente de carbonatação e a espessura de cobrimento de concreto é possível prever a vida útil da estrutura aplicando-se a Erro! Fonte de referência não encontrada. de penetração da frente de carbonatação, para avaliar o tempo até chegar na armadura [5].

$$
\begin{array}{r}
x=k_{c o 2} \cdot \sqrt{t} \\
10,2=k_{c o 2} \cdot \sqrt{ } 28 \\
k_{c o 2}=1,9276
\end{array}
$$

A partir do resultado médio de carbonatação obteve-se um coeficiente de carbonatação $k_{c o 2}=1,9276$.

Calculando o tempo de penetração de carbonatação com a Erro! Fonte de referência não encontrada. e usando o $k_{c o 2}=1,9276$ obtido verifica-se que a vida útil da estrutura, considerando o cobrimento nominal especificado em projeto de $15 \mathrm{~mm}$, seria de 60,6 anos, conforme Tabela 3, caso ocobrimento mínimo de projeto tivesse diso obedecido.

Tabela 3: Previsão de vida útil da estrutura com $\mathrm{k}$ real

\begin{tabular}{ccc}
\hline $\begin{array}{c}\text { Espessura Carbonatada } \\
\text { (mm) }\end{array}$ & $\begin{array}{c}\text { Tempo } \\
\text { (anos) }\end{array}$ & $\begin{array}{c}\mathbf{k} \\
\text { (mm.ano-1/2 })\end{array}$ \\
\hline 10,2 (medido) & 28 & 1,9276 \\
\hline 11,4 & 35 & 1,9276 \\
\hline 12,9 & 45 & 1,9276 \\
\hline 13,6 & 50 & 1,9276 \\
\hline 14,3 & 55 & 1,9276 \\
\hline 14,9 & 60 & 1,9276 \\
\hline 15,0 (projeto) & 60,6 & 1,9276 \\
\hline
\end{tabular}

\subsection{Cobrimento de armaduras}

Foram medidas as espessuras de cobrimento do concreto dos pilares para verificar se estavam atendendo ao cobrimento de projeto. 
GROSSI, M.V.F., ANÁLISE DE UM EDIFÍCIO EM CONCRETO ARMADO COM PROBLEMAS DE CORROSÃO DE ARMADURAS. $2^{\circ}$ Simpósio Paranaense de Patologia das Construções (20 SPPC), artigo 2SPPC1004 pp. 34-47, 2017. DOI:

A Figura 10 indica a frequência do cobrimento da armadura principal, onde quantificou-se que $17,2 \%$ estavam com cobrimento inferior a $1,5 \mathrm{~cm}$ especificado em projeto e $7,8 \%$ com cobrimento inferior a 10,2mm (espessura carbonatada).

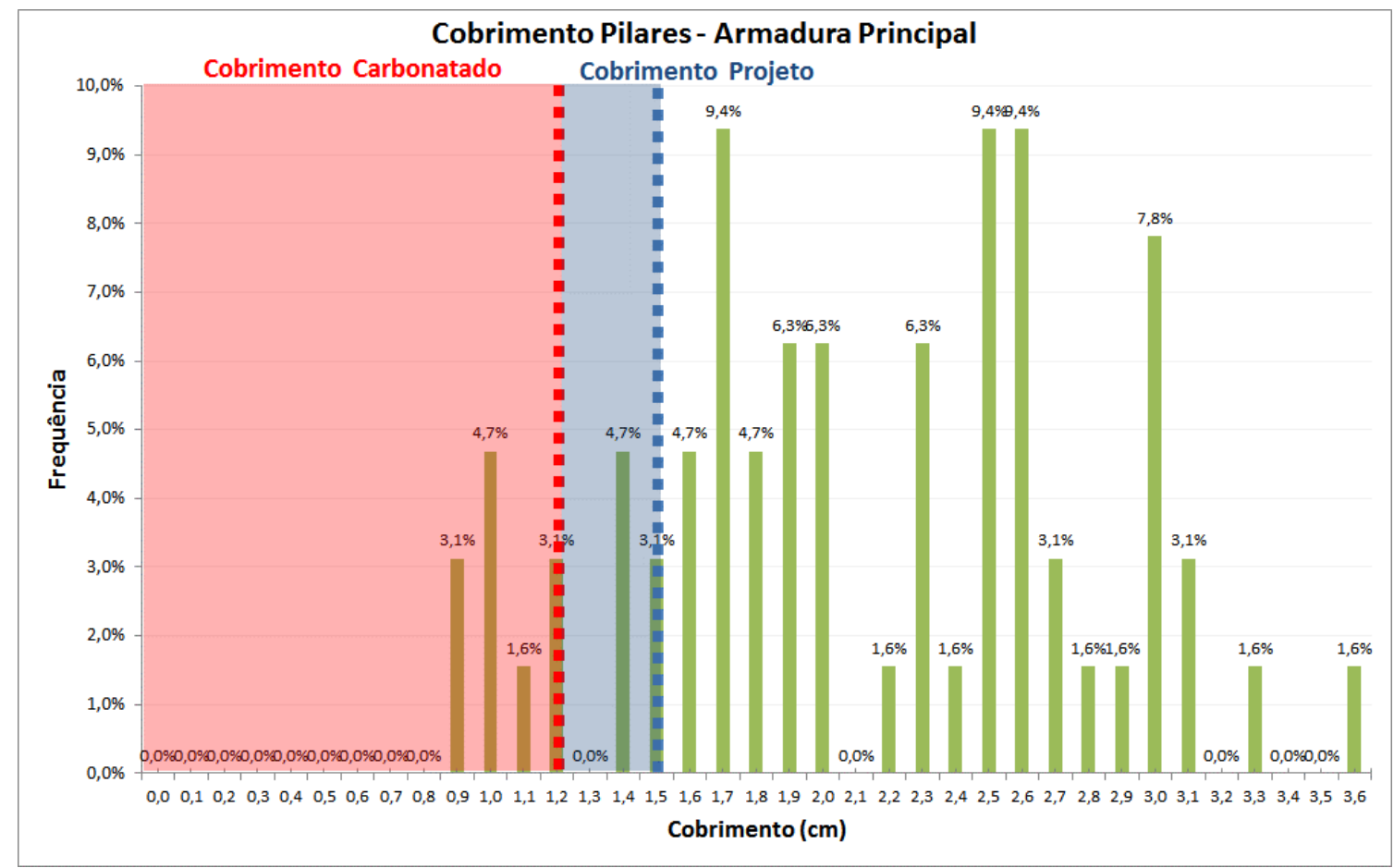

Figura 10: Frequência dos cobrimentos da armadura principal

A Figura 11 indica a frequência do cobrimento da armadura secundária (estribos), onde quantificou-se que $78,2 \%$ das armaduras estavam com cobrimento inferior a $1,5 \mathrm{~cm}$ especificado em projeto e $64,1 \%$ com cobrimento inferior a $10,2 \mathrm{~mm}$ (espessura carbonatada). 


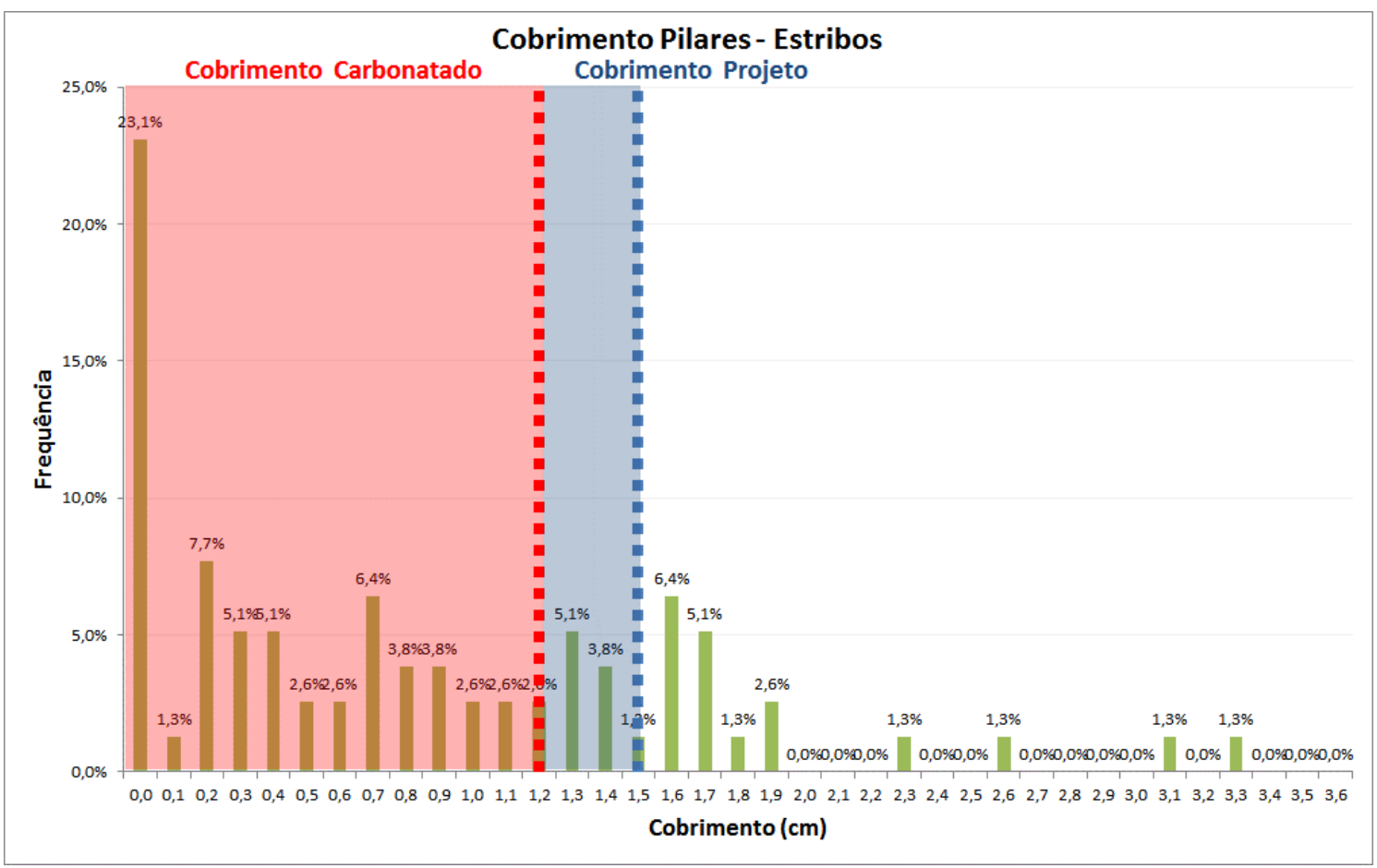

Figura 11: Frequência dos cobrimentos da armadura secundária (estribos)

Portanto $64,1 \%$ da estrutura encontra-se com algum trecho da armadura despassivada, tendo cobrimento inferior a espessura carbonatada $(10,2 \mathrm{~mm})$, o que já explica o motido da alta incidência de corrosão de armadura e desplacamentos de concreto.

\subsection{Seção das barras de aço}

Em todos os locais acessíveis com armadura exposta, foram medidos os diâmetros da seção da armadura, para verificação da redução de seção de aço.

Todos dos valores medidos estavam abaixo dos diâmetros aceitáveis do (Tabela 4) adaptado do Comite Euro-International du Beton (1983 apud Cascudo) [6], o que indica que a intencidade de corrosão não é intensa nesses pontos, ou que o processo iniciou-se a pouco tempo.

Apesar disso deverão ser medidas todas as barras oxidadas quando da realização dos reparos, para avaliar a necessidade de substituição ou acréscimo de barras.

Tabela 4: Quadro de referência para troca de barras de aço corroídas [6]

\begin{tabular}{cccccc}
\hline \multicolumn{2}{c}{ Comercial } & \multicolumn{2}{c}{ Aceitável } & \multicolumn{2}{c}{ Troca de barra } \\
\hline $\begin{array}{c}\text { Diâmetro } \\
(\mathbf{m m})\end{array}$ & $\begin{array}{c}\text { Área } \\
\left(\mathbf{m m}^{2}\right)\end{array}$ & $\begin{array}{c}-\mathbf{5 \%} \text { Área } \\
\left(\mathbf{m m}^{2}\right)\end{array}$ & $\begin{array}{c}\text { Diâmetro } \\
(\mathbf{m m})\end{array}$ & $\begin{array}{c}-\mathbf{1 0 \%} \text { Área } \\
\left(\mathbf{m m}^{\mathbf{2}}\right)\end{array}$ & $\begin{array}{c}\text { Diâmetro } \\
(\mathbf{m m})\end{array}$ \\
\hline 4,8 & 18,10 & 17,19 & 4,68 & 16,29 & 4,55 \\
\hline 6,3 & 31,17 & 29,61 & 6,14 & 28,06 & 5,98 \\
\hline 8 & 50,27 & 47,75 & 7,80 & 45,24 & 7,59 \\
\hline
\end{tabular}




\begin{tabular}{cccccc}
\hline \multicolumn{2}{c}{ Comercial } & \multicolumn{2}{c}{ Aceitável } & \multicolumn{2}{c}{ Troca de barra } \\
\hline $\begin{array}{c}\text { Diâmetro } \\
(\mathbf{m m})\end{array}$ & $\begin{array}{c}\text { Área } \\
\left(\mathbf{m m}^{\mathbf{2}}\right)\end{array}$ & $\begin{array}{c}-\mathbf{5 \%} \text { Área } \\
\left(\mathbf{m m}^{\mathbf{2}}\right)\end{array}$ & $\begin{array}{c}\text { Diâmetro } \\
(\mathbf{m m})\end{array}$ & $\begin{array}{c}-\mathbf{1 0 \%} \text { Área } \\
\left(\mathbf{m m} \mathbf{m}^{\mathbf{2}}\right.\end{array}$ & $\begin{array}{c}\text { Diâmetro } \\
(\mathbf{m m})\end{array}$ \\
\hline 10 & 78,54 & 74,61 & 9,75 & 70,69 & 9,49 \\
\hline 12,5 & 122,72 & 116,58 & 12,18 & 110,45 & 11,86 \\
\hline 16 & 201,06 & 191,01 & 15,59 & 180,96 & 15,18 \\
\hline 20 & 314,16 & 298,45 & 19,49 & 282,74 & 18,97 \\
\hline 25 & 490,87 & 466,33 & 24,37 & 441,79 & 23,72 \\
\hline 32 & 804,25 & 764,04 & 31,19 & 723,82 & 30,36 \\
\hline 40 & 1256,64 & 1193,81 & 38,99 & 1130,97 & 37,95 \\
\hline
\end{tabular}

\subsection{Desagregação do concreto}

Foram observados alguns pontos com falhas de concretagem no $2^{\circ}$ subsolo, quantificados na (Tabela 1) e ilustrados nos croquis da Figura e Figura, que possibilitam a visualização direta da armadura, conforme exemplo na (Figura 12), o que indica que sujeita ao processo de corrosão desde a execução e que não há um planejamento e realização de ações de manutenção preventiva e corretiva eficazes desse sistema.
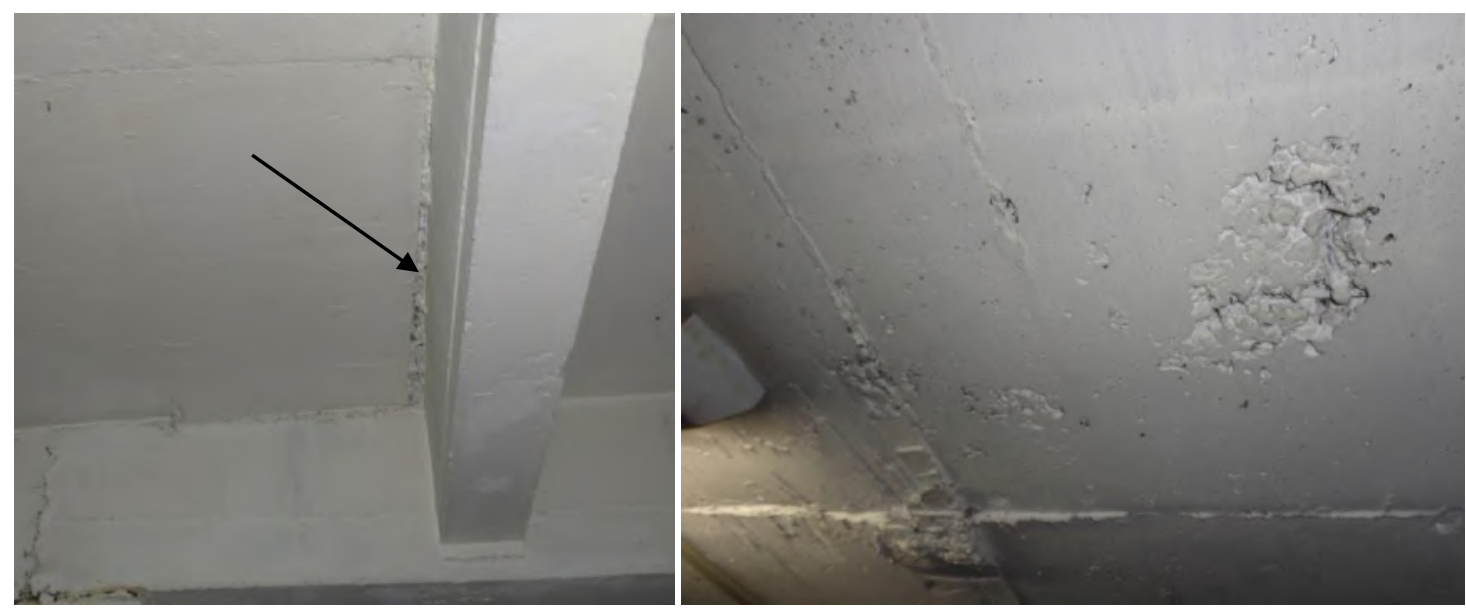

Figura 12: Ninhos de concretagem em elementos estruturais

\subsection{Reparos existentes}

É possível afirmar que o processo de corrosão das barras se dá há bastante tempo, em virtude de que foram identificados diversos pontos de reparos de desplacamento de cobrimento do concreto, conforme Figura 13. Porém, não há registros ou informações de quando foram feitos, nem de como foram feitos, gerando dúvida quanto à inibição ou bloqueio de seu processo de corrosão de maneira adequada.

Considerando que no item 4.4 foi observado a presença de ninhos de concretagem em quantidade significativa. Verificando-se que as manutenções realizadas não são orientadas de maneira correta e planejada como deveriam, pois aparentemente focam nos efeitos e não nas causas. 


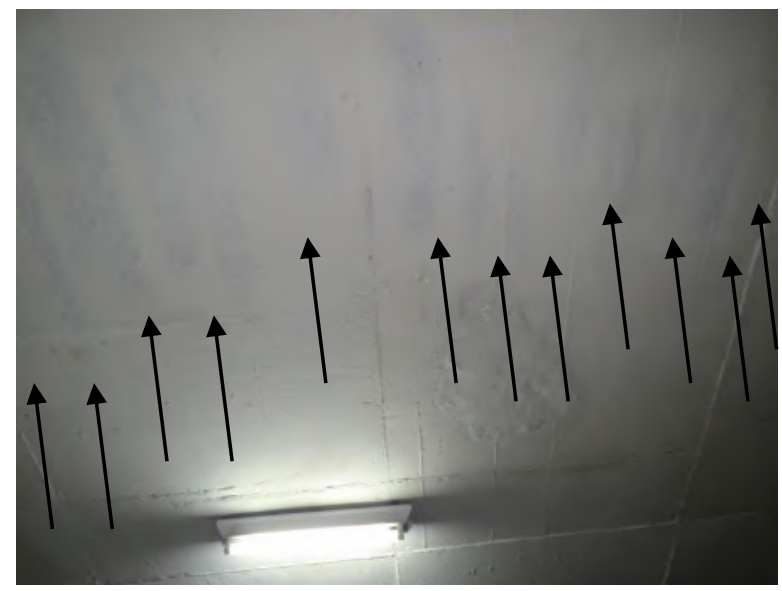

Figura 13: Reparo de armadura exposta

\subsection{Lixiviação}

Foi relatado pelo condomínio que a maioria dos pontos de infiltração identificados já tiveram sua causa sanada e que o observado são apenas os indícios residuais, pela não execução de reparo da área afetada e repintura. Porém, na maioria dos pontos com infiltração de água identificou-se, também, armadura exposta oxidada, devido ao processo de carreamento dos hidróxidos do concreto que o mantém alcalino e passiva as armaduras [1]. Além do fato de gerar um ambiente mais úmido e propício à corrosão eletrolítica da armadura [7]. Exemplo na Figura 24.
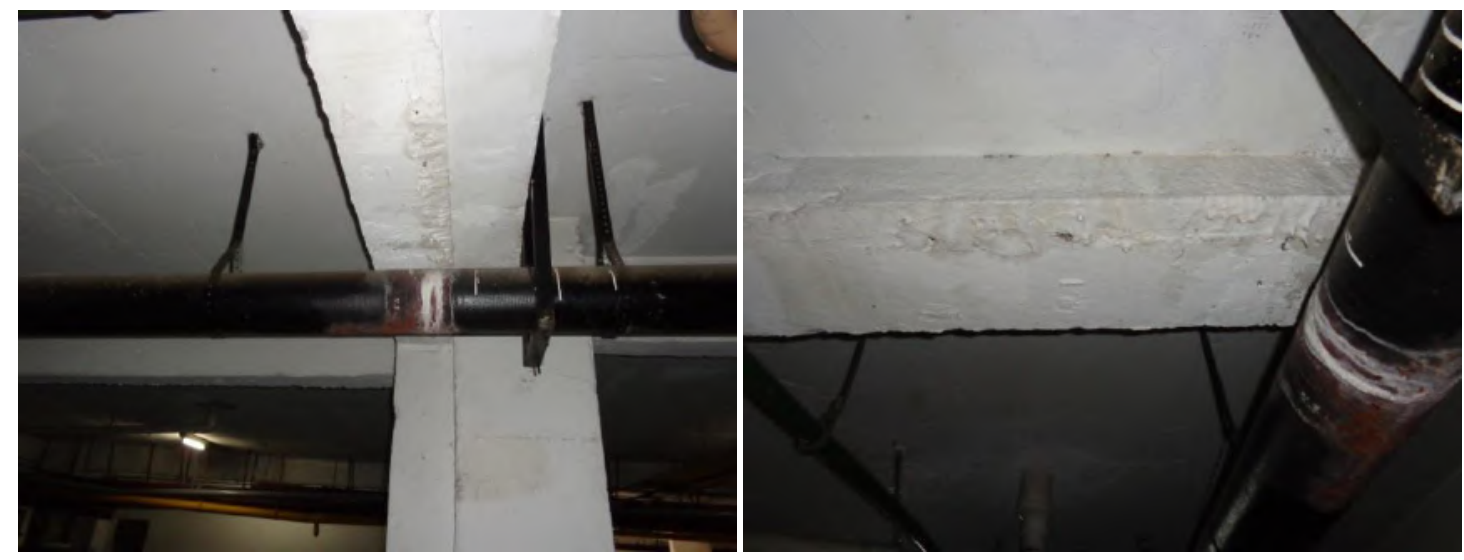

Figura 24: Infiltração em junta de movimentação com eflorescência

Além disso, também foram identificados alguns pontos de infiltração ainda ativa, com o uso de uma câmera termográfica, conforme Figura 3. Mais uma vez verificando-se que as manutenções realizadas não são orientadas de maneira correta e planejada como deveriam, não tratando as causas. 

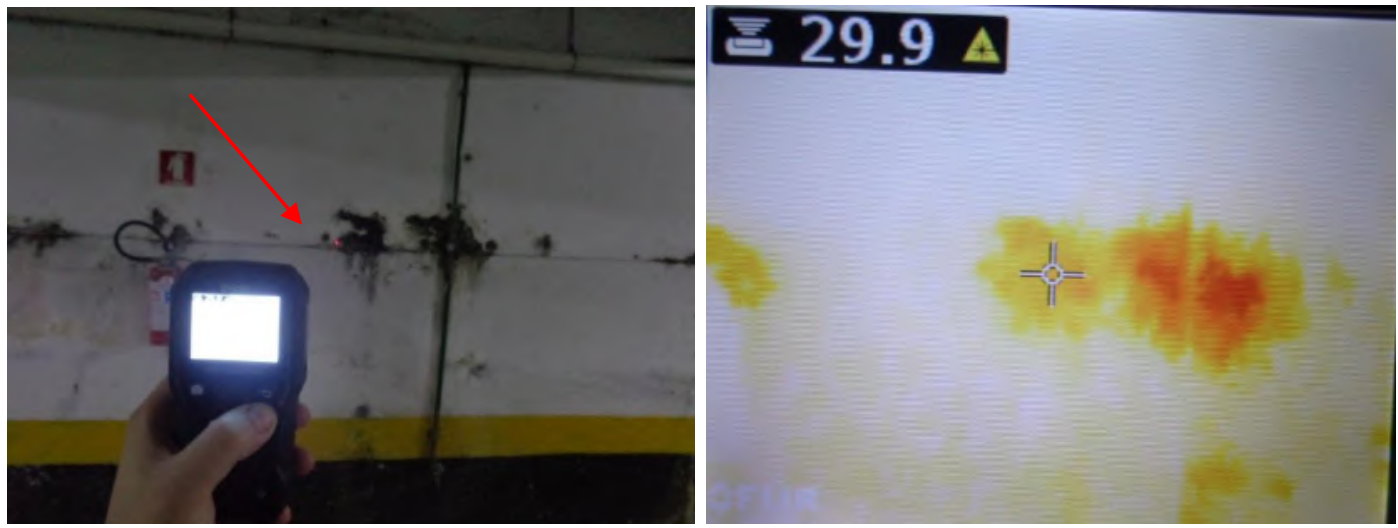

Figura 3: Mancha de identificação de infiltração em viga de divisa com termografia

\section{Conclusões}

O objetivo deste trabalho foi analisar o desempenho estrutural de um trecho da edificação, onde a estrutura é aparente, através de análise documental, inspeção visual e ensaios expeditos.

Considerando os fatos e dados obtidos, a estrutura se enquadra na classe 3 de desempenho, classificando de maneira global, conforme ABECE [1]:

Classe 3 de desempenho: Desempenho adequado ao uso com ações demandadas. Quando a estrutura não apresenta situação que impeça o uso normal da edificação, não apresenta situação que coloque em risco a segurança dos usuários, mas que apresenta manifestações de deterioração que precisam ser corrigidas para evitar que a curto prazo venham a causar o impedimento ao uso normal e o comprometimento da segurança e/ou vida útil.

As principais causas da corrosão de armaduras constatadas são:

a) O baixo cobrimento das armaduras, tanto pelo fato de não terem sido usados espaçadores quanto pela especificação da norma técnica da época;

b) A carbonatação do concreto, devido à sua baixa resistência e consequente porosidade excessiva $\left(f_{c k}=18 \mathrm{MPa}\right)$;

c) Ninhos de concretagem, que permitiram o início do processo de corrosão desde a época da execução;

d) A lixiviação do concreto devido a infiltrações, que despassivaram as armaduras devido à falta de manutenção corretiva em tempo aceitável, e devido a lavagem das garagens com água corrente, sendo que não são impermeabilizadas;

e) A adoção de concreto aparente nos subsolos sem as medidas preventivas adequadas, apenas revestido-os com pintura;

f) Também por não terem recebido repintura (manutenção preventiva).

As ações necessárias consistem no reparo de todos os pontos de corrosão, realizando a limpeza das armaduras, acréscimo de seção de aço onde necessário e recomposição do concreto. Após isso será necessário o tratamento das causas que geram a corrosão, podendo ter diversas soluções possíveis a serem estudadas. 


\section{Agradecimentos}

Ao Prof. Dr. Ércio Thomaz toda orientação durante o período de pesquisa e realização deste trabalho.

À Fernandes \& Grossi Engenheiros Associados Ltda. incentivo, materiais e recursos disponibilizados para realização das pesquisas, em especial à diretora Eng. ${ }^{\text {a }}$ Florence Nogueira Fernandes Grossi e ao sócio Eng.ำ Luiz Gustavo Fernandes Grossi.

Aos meus familiares suportarem minha ausência durante os feriados e fins de semana, em que me dedicava exclusivamente ao desenvolvimento deste trabalho.

\section{Referências}

[1] Husni, Raúl. Ações sobre as estruturas de concreto. In: HELENE, Paulo (Coord.). MANUAL DE REPARO, PROTEÇÃO E REFORÇO DE ESTRUTURAS DE CONCRETO. REPARO, REFORÇO E PROTEÇÃO. São Paulo: Red Rehabilitar, 2003. Tradução de: Osvando Braga Junior.

[2] Associação brasileira de engenharia e consultoria estrutural. Procedimentos recomendados de inspeção. Aula do Curso de Capacitação em Inspeção de Estruturas. São Paulo, 2015.

[3] Thomaz, Ércio. Recuperação de estruturas de concreto armado. Apresentação de aula da disciplina Patologia das edificações, do curso de Mestrado em Habitação: Planejamento e Tecnologia, do Instituto de Pesquisas Tecnológicas de São Paulo - IPT, São Paulo. 2016.

[4] Bristish standards institution. BS EN 14630: Products and systems for the protection and repair of concrete structures: test methods: determination of carbonation depth in hardened concrete by the phenolphthalein method. London, United Kingdom, 2006.

[5] Helene, Paulo. Vida útil das estruturas de concreto. Anais: $4^{\circ}$ Congresso lberoamericano de Patologia das Construções e $6^{\circ}$ Congresso de Controle da Qualidade, CON-PAT 97. Porto Alegre, UFRGS, 21 a 24 out. 1997.

[6] Cascudo, Oswaldo. O controle da corrosão de armaduras em concreto: inspeção e técnica eletroquímicas. Prefácio Paulo Helene. São Paulo: Editora PINI. Goiânia - GO: Editora UFG, 1997.

[7] Alconpat Internacional. Boletín Técnico 06: Corrosión de armadura de estructuras de hormigón. Merida - México, 2013. 